\section{Science petitions are a facade of numbers}

University, New Haven,

Connecticut, USA.

Scientists and science organizations increasingly use petitions to influence public opinion and government decisions, and the practice is now spilling over into peer-reviewed journals. We question the effectiveness of public petitions, and suggest that ganging up against unpopular research risks damaging scientific discourse.

Petitioners recruit researchers as co-signatories to reinforce their argument, often for people who may not fully understand the debate. Last year, for example, 31,000 scientists signed a petition rejecting the idea of global warming (www.petitionproject. org) - but a counter-petition with 31,001 signatures won't resolve the debate. Numbers and scientific argument generally have little influence on public opinion or political decisions (D. Ding et al. Nature Clim. Change 1, 462-466; 2011), partly because of the difficulty in assessing the authority of individual co-signatories.

'Gang science' is being used to quash unpopular ideas in peer-reviewed journals. For example, 141 scientists mounted an attack on proposals for managing introduced species (D. Simberloff et al. Nature 475,$36 ; 2011$ ), and 137 others challenged a paper written by three authors on the evolution of eusociality (P. Abbot et al. Nature 471, E1-E4; 2011). In the absence of new data, such huge conglomerates contribute little more than intimidation.

We should judge the validity of scientific ideas on hard, replicable data and not on the number of authors. Otherwise, scientists risk being branded as another advocacy group with its own agenda.

Robert J. Warren Buffalo State, State University of New York, Buffalo, New York, USA. warrenrj@buffalostate.edu Mark A. Bradford Yale

\section{Small collections make a big impact}

In an era in which support for natural-history collections is waning, we wish to point out how effective even a small, young collection can be.

We constructed a Google Scholar profile (called UAM Birds) of publications that used the bird collection we oversee at the University of Alaska Museum in Fairbanks. The collection is supported by 1.3 full-time-equivalent staff, and it served in whole or in part as research infrastructure for these publications, contributing and preserving specimens and associated information.

The body of work supported by the collection is diverse and well cited, with a profile $h$-index of 42 , equivalent to an average Nobel laureate in physics (J. E. Hirsch Proc. Acad. Natl Acad. Sci. USA 102, 16569$16572 ; 2005)$. This positively sings 'good investment' and should encourage other institutions to rediscover and reinvest in collections as important societal resources. Kevin Winker, Jack J. Withrow University of Alaska Museum, Fairbanks, Alaska, USA. kevin.winker@alaska.edu

\section{Obesity: multiple factors contribute}

The idea that obesity is mainly caused by a high intake of carbohydrate is only one of many possible explanations (G. Taubes Nature 492, 155; 2012). The energy in-energy out hypothesis may also be valid, but it is likely to be an oversimplification.

It is important to consider the body's requirements for key nutrients such as the essential amino acids, as well as for energy. A high-energy diet deficient in these can lead to malnutrition coupled to obesity.

Scientists need to take a closer look at the effects of dietary protein, lipid and carbohydrate on appetite and food intake. These should be assessed in the context of hormone regulation of intermediary metabolism and the large variation in basal metabolic rate among individuals.

We shall then have a more accurate basis for advising Western populations on how to avoid obesity.

Kristin Hamre National Institute of Nutrition and Seafood Research, Bergen, Norway. kha@nifes.no

\section{Obesity: appetite hormone weighs in}

Gary Taubes suggests that obesity researchers are currently focusing on energy balance at the expense of hormonal factors (Nature 492, $155 ; 2012$ ), but hormonal factors have always been an important part of obesity research.

The German physician Bernard Mohr first described human obesity associated with abnormalities of the basal hypothalamus more than 170 years ago (Wochenschr. Ges. Heilkunde 6, 565-571; 1840). In the second half of the twentieth century, a negative feedback loop gradually became evident between the hormone leptin (produced by fat cells) and the hypothalamus, which has turned out to be a crucial regulator of levels of body fat.

Since leptin's discovery in 1994, nearly 10,000 papers have appeared in PubMed on the involvement of leptin signalling in obesity.

Stephan J. Guyenet University of Washington, Seattle, USA. guyenet@uw.edu

\section{Undo NIH policy to ease effect of cuts}

You say that a petition by US biomedical scientists against the one-retry limit on grant applications to the National Institutes of Health (NIH) was "beside the point", despite acknowledging the validity of their arguments (Nature 492, 7; 2012). As the petition's author, I disagree: trying to correct a poor policy decision is not the entire point, as we all recognize, but it is most certainly part of the point.

We believe that the petition - which has now been signed by more than 3,000 scientists (see go.nature.com/x5tik5) outweighs the questionable arguments for retention of the policy put forth by the NIH (see go.nature.com/mwfqel).

In our view, NIH study sections cannot distinguish the quality of proposals in the first quartile. Therefore, once the percentage of applications being funded falls significantly below the 25th percentile, those in the first quartile that go unfunded should be allowed to resubmit as many times as they wish because they are equal in merit to those that are funded.

We are not in the grip of an "unhealthy" obsession, as you suggest. The NIH's unfair decision could be undone with the stroke of a pen, which would help to ease these tough times for biomedical research. We urge scientists to continue working on all fronts to contain the damage caused by reduced federal spending on research.

Robert Benezra Memorial Sloan-Kettering Cancer Center, New York, USA.

benezrar@mskcc.org

\section{Chance thrown by inaccurate dice}

The beauty of six-sided dice is that the spots on opposite sides add up to seven - a six and a one, five and two, and four and three. Your illustration wrongly depicts these pairs on adjacent sides (Nature 492, 34-36; 2012). Janet K. Burg Eugene, Oregon, USA.

bmeerkat@comcast.net 